\title{
O jogo tradicional na formação vocal do estudante de graduação em teatro
}

\author{
Eugenio Tadeu Pereira \\ Doutorando em Artes Cênicas/USP \\ Área de Concentração: Pedagogia do Teatro \\ Orientadora: Dra. Maria Lúcia Pupo. \\ Bolsa Prodoutoral/ CAPES \\ Professor Assistente na Escola de Belas Artes da UFMG / Duo Rodapião / Serelepe
}

Resumo: a pesquisa teve como objetivo analisar e discutir a relevância de práticas vocais lúdicas na formação de estudantes de licenciatura e bacharelado em teatro. Nesse estudo, os jogos tradicionais e a reflexão foram os propiciadores dessa experiência formativa. Diante dos dados analisados, estamos concluindo que essa modalidade de jogo contribui na formação vocal desses sujeitos, levando-os à compreensão e à apropriação dos parâmetros sonoros, de atitudes técnicas e de procedimentos criativos com a voz.

Palavras-chave: prática vocal, jogo tradicional e voz, experiência vocal lúdica, pedagogia do teatro

Title: The traditional game of vocal training in a graduate student in theater

Abstract the research aimed to analyze and discuss the relevance of playful vocal practices of teaching education and bachelor degrees students in theater. In this study, traditional games and the reflection were the promoters of the formative experience. From the data analyzed, we are concluding that this type of game helps in training these individuals' voices, leading them to understand and appropriate the sound parameters, technical attitudes and creative procedures with the voice.

Keyswords: vocal practice, traditional game and voice, vocal play experience, pedagogy of the theatre

Título: El juego tradicional de la formación vocal en un estudiante graduado en el teatro Resumen: la investigación tuvo como objetivo analizar y discutir la relevancia de prácticas vocales lúdicas en la formación de estudiantes de pedagogía y bachillerato en teatro. En el estudio, los juegos tradicionales y la reflexión fueron los principales propiciadores de esta experiencia formativa. De acuerdo con los datos analizados, estamos concluyendo que esta modalidad de juego contribuye a la formación vocal de estos sujetos, llevándolos a la comprensión y a la apropiación de los parámetros sonoros, de actitudes técnicas y de procedimientos creativos con la voz.

Palabras-clave: práctica vocal, juego tradicional y voz, experiencia vocal lúdica, pedagogía de teatro 
A sala de aula universitária é um espaço privilegiado para a exploração e a construção do conhecimento devido à diversidade de procedimentos que, nela, podem ser utilizados com esses objetivos. De nossa parte, elegemos o jogo, que é constituído pela interação e pela atividade exploratória, como um mediador de experiências formativas.

Utilizamos a situação lúdica como desencadeadora de reflexão, de conhecimento técnico, de criação e de aprimoramento vocal, direcionando, assim, o percurso dos trabalhos em nossa pesquisa "Práticas lúdicas na formação vocal em teatro" com os estudantes nas aulas da disciplina "Oficina de Improvisação Vocal e Musical", do Curso de Graduação em Teatro - Licenciatura e Bacharelado -, da Escola de Belas Artes, da Universidade Federal de Minas Gerais (EBA/UFMG), durante o primeiro semestre de 2010.

Buscamos uma experiência nesse microespaço social fundamentada na descoberta de diferentes possibilidades sonoras com a voz. Queríamos também propor uma contínua reflexão no processo de aprendizagem para, dessa forma, provocar nos estudantes um fazer reflexivo. A experiência, como afirma John Dewey, não advém de uma simples atividade, pois exige algum tipo de reflexão para que se torne significativa (DEWEY, 1959). É com base em uma situação dessa natureza que o sujeito vai dar significado ao ato e projetar novas ações. Nessa perspectiva, a díade prática e reflexão é fundamental para a constituição do conhecimento na sala de aula universitária.

Esse lugar de ensino é caracterizado por ações flexíveis, e muitas vezes imprevisíveis, que são conduzidas por regras que não são fixas, pois se modificam de acordo com os sentidos apreendidos no instante em que as ações são realizadas. O papel do professor pesquisador nesse temenos ${ }^{1}$ pedagógico, como o gerenciador dos acontecimentos, é também afetado; ele revê, adapta, reflete e reordena o roteiro de curso de acordo com o que acontece. A maneira como as situações nessa sala ocorrem impele esse sujeito a estabelecer as relações entre o conteúdo, os procedimentos, as respostas dos estudantes e os eventos extemporâneos. Dessa forma, a sala de aula universitária é, levando em conta os princípios lançados por Luigi Pareyson, um espaço para experiências de formatividade (PAREYSON, 1993). Para esse pensador, enquanto a atividade acontece, inventamos e descobrimos as regras que a fazem acontecer. 
Uma vez que o processo se deu conjuntamente aos estudantes e que eles se tornaram participantes ativos da pesquisa, optamos por utilizar instrumentos da pesquisa-ação como metodologia de trabalho. A pesquisa-ação, afirmam René Barbier e Michel Thiollent, é aquela em que o pesquisador está enredado com o objeto e com os sujeitos envolvidos. Ela é uma investigação empírica que se caracteriza por ações em torno de questões nas quais os participantes e pesquisadores estão envolvidos de modo cooperativo e reflexivo. Essa modalidade de pesquisa sujeita o pesquisador a inserir-se no grupo e insere o grupo na pesquisa (BARBIER, 2004; THIOLLENT, 2007).

Para a coleta de dados, tivemos como instrumentos os protocolos, o diário de itinerância, os papers e registro audiovisual. Essas ferramentas nos possibilitaram fazer o cruzamento dos dados obtidos e inferir sobre a pertinência do uso dos jogos na formação vocal daqueles estudantes.

Os temas de estudos, eleitos para o programa de trabalho em sala de aula, foram: a produção vocal, os recursos vocais, a atitude técnica, os parâmetros sonoros e a musicalidade, a escuta, a repetição no aprimoramento do uso vocal e o corpo como lugar da voz. Além desses temas, tivemos o conceito de jogo como objeto de reflexão.

$\mathrm{Na}$ emissão vocal, o sujeito dispõe de recursos que são provenientes de um complexo sistema chamado aparelho fonador que age no instante em que a voz é produzida. Com certeza esse sistema não é um órgão, mas uma conjunção de distintas partes de vários órgãos, cujo processo passa pelos comandos cerebrais, pelas atividades musculares na laringe, pelas vibrações das cordas vocais e pela ressonância no corpo como um todo.

A voz que surge nesse complexo é formada de acordo com a constituição física do sujeito e de sua relação com o meio social. Esse sujeito é compreendido como uma unidade psicofísica (ALEXANDER, 1992) que constrói sua vocalidade (ZUMTHOR, 1993) ou a historicidade do uso de sua voz no contexto cultural onde ele é constituído.

Para nós, a maneira pela qual o estudante executa um determinado exercício influencia em seu resultado final. Sendo assim, os procedimentos de caráter lúdico nas atividades podem proporcionar a esse sujeito a apropriação de procedimentos de emissão vocal, a reflexão sobre esses procedimentos e fazer com que ele experimente o potencial de sua voz no contexto de sua formação. 
Tomamos como princípios do jogo as características assinaladas por John Huizinga e Roger Caillois. Para esses autores, a situação lúdica se caracteriza por uma atividade livre e voluntária; por ações de caráter fictício e delimitadas no espaço e no tempo; por ser improdutiva e destituída de interesse material; por abrigar um resultado incerto e por ser realizada com regras acordadas e seguidas obrigatoriamente pelos jogadores (HUIZINGA, 1993; CAILLOIS, 1990).

Observamos também outros estudos que caracterizam o jogo como um espaço para a exploração e a invenção com os materiais e temas escolhidos pelos jogadores, como afirmam Gilles Brougère (1998), Jerome Bruner (1986), Stephen Nachmanovitch (1993) e Jean-Pierre Ryngaert (2009).

Além desses referenciais, tomamos como princípios os indicadores de uma atividade lúdica citados por Lino de Macedo, Ana Petty e Norymar Passos. Segundo esses autores, a atividade lúdica em sala de aula deve ser baseada no prazer funcional, na proposição de desafios, na criação ou na organização de possibilidades, na apresentação da dimensão simbólica e na permissão para os jogadores poderem se expressar de modo construtivo ou relacional (MACEDO; PETTY; PASSOS, 2005, p. 15).

Quando esses princípios estão na base de nossas ações, observamos que os estudantes têm a possibilidade de transformar muitos procedimentos técnicos - tais como a respiração diafragmática, a mudança de timbre vocal, o uso de parâmetros sonoros musicais, entre outros - em atividades com vestígios de jogo.

Segundo Janaína Martins, “o prazer que envolve o jogo, na ludicidade do pesquisar, do conhecer a si, do expressar, do escutar, do compartilhar, do brincar, permite que o processo criativo flua em potencial" (2008, p. 33). O fluxo criativo proporcionado pelo jogo é decorrente das estruturas que esse tipo de situação apresenta, uma vez que ela promove o engajamento do sujeito na atividade e é um campo de liberdade de ação dentro dos limites das regras.

De acordo com Ryngaert, “o jogo é um recurso contra a rotina da representação cotidiana, contra o fechamento do teatro numa rede de técnicas enrijecidas” (2009, p. 61). Acreditamos que o jogo não é somente um recurso para o cotidiano da representação, mas também para os processos que ocorrem no interior da sala de aula, 
pois é nesse lugar que se constitui um modo de trabalho e estudo que vai repercutir na formação e no exercício profissional desse estudante.

Entre as várias modalidades de uma situação lúdica, o jogo tradicional foi eleito como foco de estudo para esse trabalho. Esse tipo de jogo se caracteriza por "anonimato, tradicionalidade, transmissão oral, conservação, mudança e universalidade" (KISHIMOTO, 1993, p. 15); ou seja, não se sabe quem é o autor ou a autoria se perde no tempo; ele é transmitido de uma geração à outra e quase sempre de forma oral; ele é mantido em sua estrutura básica e absorve modificações de acordo com o meio onde é praticado, sendo inseridos novos conteúdos ou regras em sua estrutura; e, por fim, o jogo tradicional tem uma característica de universalidade, pois podemos encontrá-lo em diferentes culturas e épocas.

Um repertório dessas atividades, como - amarelinha, pular corda, soltar pipa, jogar pedrinhas e brincar de pega-pega, entre tantas outras - permanece em nosso meio desde a antiguidade. Muitos desses jogos têm origem nos romances, poesias, mitos e rituais religiosos; essas são situações abandonadas por grupos humanos, sendo, em seguida, apropriadas em diferentes contextos e segmentos sociais (CASCUDO, 1984; KISHIMOTO, 1998).

Para a análise dos dados da pesquisa, elegemos os seguintes jogos, que se destacaram quanto à sua função de explicitar os temas estudados: Bate o monjolo (MG), Casinha de Bambuê (MG), Chep chep (BA), Faquinha da roça (MG), Lá vai o ganso (MG), Mamenê (África), Pega Pega (MG), Pular corda (MG) e Quatro Cantos (MG). Essas atividades proporcionaram a exploração vocal a partir dos parâmetros sonoros altura, duração, timbre e intensidade - e questões musicais como andamento, cânone e ritmo.

O jogo tradicional teve correspondência com o objetivo geral da pesquisa, que era: analisar e discutir o interesse, a pertinência e a relevância de procedimentos vocais de caráter lúdico na formação dos estudantes de licenciatura e bacharelado em teatro.

Esse tipo de situação lúdica cria um campo favorável para o enfrentamento de situações em que o jogador é desafiado a descobrir e a inventar resoluções para as questões postas na atividade. No jogo tradicional, há esse tipo de desafio que move os jogadores a confrontarem sua habilidade com as condições apresentadas pela 
circunstância. Esse enfrentamento é referenciado nas regras estabelecidas pelos jogadores. Nessa relação, o sujeito se vê diante de situações que demandam uma tomada de atitude e que lhe exigirá escuta, perspicácia e capacidade de relacionar os fatos entre si para, então, decidir como agir e sobre o que atuar.

Em qualquer modalidade de jogo as interações são construídas no instante em que a situação lúdica acontece. É uma relação no aqui e agora que o jogador estabelece com seus parceiros e com o ambiente, afirma Maria Lúcia Pupo (2001). Para essa autora, as interações "implicam intencionalidade, mas incluem também, necessariamente, fatores aleatórios" (PUPO, 2001, p. 182). A imprevisibilidade dos jogos nos abre um caminho fecundo para a sua exploração, para a descoberta de soluções não previstas e para o exercício criativo.

Durante os trabalhos observamos que os estudantes assimilaram a atitude de jogo em muitas situações em sala de aula, inclusive na prática de procedimentos técnicos, nos aquecimentos e nas atividades em geral, como já mencionamos. Nessa perspectiva, a estudante Camila Vaz faz o seguinte depoimento, em um de seus protocolos:

\footnotetext{
E por mais que entramos num jogo apenas brincando, não nos foge da mente que não somos mais crianças e que estamos dentro da universidade aprendendo. Com isso, cada integrante do grupo está altamente comprometido e preocupado, não só com as regras do jogo, mas também com as percepções corporais trabalhadas anteriormente, como a utilização do apoio abdominal para o uso da voz, a escuta, a visão de todos os ângulos, inclusive das nossas próprias costas, o não se concentrar olhando para dentro de si, entre outros.
}

Constatamos que o uso do jogo na sala de aula universitária provoca desafios, descobertas, explorações e procedimentos criativos com a voz. A situação lúdica tradicional, agindo em conjunto com uma ação reflexiva, instaura um campo favorável para o uso das potencialidades e habilidades vocais dos estudantes. Ela propicia a compreensão e a assimilação desses processos e contribui, dessa maneira, na formação daqueles que desejam atuar nos campos da docência e da atuação teatral. 


\section{Referências}

ALEXANDER, F. M. $O$ uso de si mesmo: a direção consciente em relação com o diagnóstico, o funcionamento e o controle da reação. São Paulo: Martins Fontes, 1992.

BARBIER, René. A pesquisa-ação. Brasília: Liber Livro, 2002.

BROUGÈRE, Gilles. A criança e a cultura lúdica. In: KISHIMOTO, Tizuko M. (Org.). O brincar e suas teorias. São Paulo: Pioneira, 1998.

BRUNER, J. S. Juego, pensamiento y lenguaje. Perspectivas, UNESCO, vol. 16 (1), 1986.

CASCUDO, Câmara. Dicionário do folclore brasileiro. 5. Ed. Belo Horizonte: Itatiaia, 1984.

DEWEY, John. Democracia e educação - Introdução à filosofia da educação. São Paulo: Companhia Editora Nacional, 1959.

HUIZINGA, John. Homo ludens. São Paulo: Perspectiva, 1993.

KISHIMOTO, Tizuko Morchida. Jogos tradicionais infantis. Rio de Janeiro: Vozes, 1993.

KOUDELA, Ingrid Dormien. Jogos teatrais. São Paulo: Perspectiva, 2002.

MACEDO, Lino de; PETTY, Ana L. S.; PASSOS, Norimar C. Os jogos e o lúdico na aprendizagem escolar. Porto Alegre: Artmed, 2005.

MARTINS, Janaína Träsel. Os princípios da ressonância vocal na ludicidade dos jogos de corpo-voz para a formação do ator. Tese (Doutorado em Artes Cênicas) - Escola de Teatro, Universidade Federal da Bahia, Salvador, 2008.

NACHMANOVITCH, Stephen. Ser Criativo - O poder da improvisação na vida e na arte. São Paulo: Summus, 1993.

PAREYSON, Luigi. Estética: Teoria da Formatividade. Petrópolis: Vozes, 1993.

PUPO, Maria Lúcia de Souza Barros. O lúdico e a construção do sentido. Sala Preta, São Paulo, Escola de Comunicações e Artes, Universidade de São Paulo, n. 1, p. 181187, 2001.

RYNGAERT, Jean-Pierre. Jogar, representar - Práticas dramáticas e formação. São Paulo: Cosacnaify, 2009.

THIOLLENT, Michel. Metodologia da pesquisa-ação. 15. ed. São Paulo: Cortez, 2007.

ZUMTHOR, Paul. A letra e a voz: a "literatura" medieval. São Paulo: Companhia das Letras, 1993. 
Revista "AspaS" - N01 - 2011 - Anais do Primeiro Seminário de Pesquisas em Andamento ppgac do Programa de Pós-Graduação em Artes Cênicas da Universidade de São Paulo.

${ }^{1} \mathrm{O}$ temenos era um lugar "separado e afastado do mundo vulgar", onde se ministrava a justiça na Grécia Antiga (HUIZINGA, 1993, p. 88); era um "círculo mágico, um espaço sagrado dentro do qual a atividade estava sujeita a regras especiais e acontecimentos extraordinários podiam ocorrer livremente" (NACHMANOVITCH, 1993, p. 76). 